\title{
Effect of coagulation mechanism on membrane permeability in coagulation-assisted microfiltration for spent filter backwash water recycling
}

\author{
Chihpin Huang a , Jr-Lin Lin ${ }^{\mathrm{a}}$, Wen-Shan Lee ${ }^{\mathrm{a}}$, Jill R. Pan ${ }^{\mathrm{b}, *}$, Bingqing Zhao ${ }^{\mathrm{c}}$ \\ a Institute of Environmental Engineering, National Chiao Tung University, Hsinchu, Taiwan \\ b Department of Biological Science and Technology, National Chiao Tung University, 75 Po-Ai Street, Hsinchu, Taiwan \\ ' State Key Laboratory of Environmental Aquatic Chemistry, Research Center for Eco-Environmental Sciences, Chinese Academy of Sciences, Beijing 100085, PR China
}

\section{A R T I C L E I N F O}

\section{Article history:}

Received 6 November 2010

Received in revised form 17 January 2011

Accepted 28 January 2011

Available online 3 March 2011

\section{Keywords:}

Micro-filtration

Coagulation

Membrane flux

Spent filter backwash water

\begin{abstract}
A B S T R A C T
Coagulation is an effective pre-treatment process in membrane filtration for recycling spent filter backwash water (SFBW). To optimize the operation of the coagulation/filtration process for SFBW recycling, it is important to understand the critical role of coagulation mechanism on membrane filtration. In this study, SFBW samples were coagulated with polyaluminum chloride ( $\mathrm{PACl}$ ), followed by a dead-end microfiltration (MF), and the mean permeate flux and permeate quality were determined. The results showed that pre-coagulation improved the flux decline and the degree of the improvement was closely related to coagulation mechanisms. The permeate flux was enhanced most effectively by precipitation charge neutralization (PCN) coagulation, followed by charge neutralization and then sweep flocculation. Close examination of cake properties indicated that the reduced cake resistance $\left(R_{c}\right)$ was subjected to the coagulated SFBW flocs in response to different coagulation mechanism. Smaller flocs, induced by PCN, were more compact and stronger, forming less compressible cake, which facilitated membrane filtration, while slower membrane filtration was observed when more compressible cake formed from larger flocs of looser and weaker structure. Coagulation mechanism also governed the size distribution of SFBW floc, which is strongly related to the subsequent cake compressibility as well as membrane permeability in membrane filtration.
\end{abstract}

(C) 2011 Elsevier B.V. All rights reserved.

\section{Introduction}

Filter backwashing is essential to the operation of a water treatment plant (WTP) in order to maintain efficient filtration. During filter backwashing, the accumulated impurities are dislodged from the filter, and spent filter backwash water (SFBW) is generated, which contains colloidal materials, living organisms and natural organic matter, inorganic metals (e.g., aluminum and iron), and other impurities [1-3]. On average, approximately $2-10 \%$ of the finished water is used for backwashing in each WTP [4-6]. The SFBW is normally recycled to the influent stream of the WTP. Studies have found the presence of pathogens such as Giardia and Cryptosporidium, and precursors for disinfection by-product (DBPs) in SFBW $[7,8]$. Therefore, direct recycling of SFBW could jeopardize the quality of the finished water due to the concentration of contaminants during the recycling [9].

Membrane separation has been an option for wastewater reclamation in drinking water treatment processes $[10,11]$. Studies have

\footnotetext{
* Corresponding author. Tel.: +886 3 5726463; fax: +886 35725958.

E-mail address: jrpan@mail.nctu.edu.tw (J.R. Pan).
}

indicated that pathogens, DBPs and particulate contaminants in SFBW can be effectively removed by processes such as microfiltration (MF) or ultrafiltration (UF) [12,13]. In addition, SFBW recycling by dead-end membrane has been proved economically feasible [14]. However, as in all membrane filtrations, membrane fouling is the impediment because it can reduce the permeate flux and increase the burden of membrane cleaning.

One important method to retard membrane fouling is a hybrid coagulation/membrane separation process, in which coagulation is performed ahead of the membrane separation by enlarging flocs for fouling mitigation [15-18]. In such an operation, Al-based coagulants are generally used. However, inconsistent results for filtration performance were observed due to the variation in floc structure under different operating conditions, such as $\mathrm{pH}$ and the dosage of coagulants [19-21]. Researchers have also suggested that the enhancement of membrane permeability was strongly related to the strength and size distribution of the flocs [22-26]. For Al-based coagulation, the property of the flocs is dictated by the mechanism of coagulation induced by various hydrolyzing Al species [27]. Mechanisms of coagulation by hydrolyzing these include charge neutralization of negatively charged colloids and incorporation of impurities into an amorphous hydroxide precipitate (i.e., sweep flocculation) [28]. Electrostatic patch and interparticle bridging 


\begin{tabular}{|ll|}
\hline \multicolumn{2}{|l|}{ Nomenclature } \\
$J$ & permeate flux $\left(\mathrm{L} \mathrm{m}^{-2} \mathrm{~h}^{-1}\right)$ \\
$J_{0}$ & clean water flux $\left(\mathrm{L} \mathrm{m}^{-2} \mathrm{~h}^{-1}\right)$ \\
$J_{1}$ & flux of coagulated samples $\left(\mathrm{L} \mathrm{m}^{-2} \mathrm{~h}^{-1}\right)$ \\
$J_{2}$ & clean water flux after backwash of filtered mem- \\
& brane $\left(\mathrm{L} \mathrm{m}^{-2} \mathrm{~h}^{-1}\right)$ \\
$A_{m}$ & membrane area $\left(\mathrm{m}^{2}\right)$ \\
$V$ & cumulative permeate volume $\left(\mathrm{m}^{3}\right)$ \\
$C_{b}$ & the bulk concentration of particles $\left(\mathrm{kg} \mathrm{m}^{-3}\right)$ \\
$\alpha$ & specific cake resistance $\left.(\mathrm{m} \mathrm{kg})^{-1}\right)$ \\
$n$ & compressibility index \\
$\mu$ & viscosity (Pa s) \\
$\Delta P$ & transmembrane pressure $(\mathrm{Pa})$ \\
$R_{t}$ & total resistance $\left(\mathrm{m}^{-1}\right)$ \\
$R_{m}$ & membrane resistance $\left(\mathrm{m}^{-1}\right)$ \\
$R_{f}$ & fouling resistance $\left(\mathrm{m}^{-1}\right)$ \\
$R_{C}$ & cake resistance $\left(\mathrm{m}^{-1}\right)$ \\
& \\
\hline
\end{tabular}

have also been proposed to interpret coagulation behavior of various polyaluminum chloride ( $\mathrm{PACl})$ coagulants and the resulting flocs composition [29-31].

Many previous investigations of SFBW recycling by coagulation/microfiltration process have suggested that optimizing pre-coagulation conditions can enhance the quality and quantity of the filtrate [32,33]. In a study of coagulation/dead-end microfiltration on SFBW, Huang et al. [34] reported that SFBW had a wide size distribution, ranging from submicron to micron scale. Optimal PACl coagulation was achieved when the majority of the submicron particles were enlarged, which delayed the pore plugging in the filtration membrane. These results imply that the membrane filtration of SFBW can be affected by manipulating the pre-coagulation mechanisms. However, the effect of coagulation mechanism on membrane permeability for SFBW recycling by coagulation-assisted dead-end microfiltration process remained unclear, and most studies were small-scale laboratory tests which provided little information about the long-term relationship between coagulation mechanisms and membrane filtration behavior of SFBW. In this study, a coagulation/dead-end MF process was simulated in which $\mathrm{PACl}$ was used as coagulant. Floc formation as well as floc strength during coagulation were monitored, and the corresponding resistances to membrane filtration were determined. The quality of the permeate was evaluated to determine the efficiency of the hybrid coagulation/membrane filtration.

\section{Materials and methods}

\subsection{Materials}

\subsubsection{Water sample}

SFBW samples were collected from the backwash discharge of a traditional sand filtration of the Hsinchu Water Treatment Plant (Hsinchu WTP) in Hsinchu, Taiwan. The filters were backwashed with the finished water for 10 min once every $24 \mathrm{~h}$. Since the composition and turbidity of the SFBW fluctuated during backwashing, each SFBW sample was the mixture of several collections from one backwash cycle at fixed intervals. Characteristics of the SFBW samples are summarized in Table 1.

\subsubsection{Coagulants}

A commercial PACl product $\left(\mathrm{Al}_{2} \mathrm{O}_{3}=10 \% ; \gamma=1.4\right)$, which contained insignificant amount of sulfate, was purchased from Showa Chemicals Inc. and was used as the coagulant in this study. The
Table 1

Characteristics of SFBW samples and the permeate after membrane filtration coupled with pre-coagulation by PCN, CN and SW.

\begin{tabular}{|c|c|c|c|c|}
\hline \multirow[t]{2}{*}{ Parameters } & \multirow{2}{*}{$\begin{array}{l}\text { Raw water } \\
\text { SFBW }\end{array}$} & \multicolumn{3}{|c|}{ Permeate $^{a}$} \\
\hline & & PCN & $\mathrm{CN}$ & SW \\
\hline $\mathrm{pH}$ & 7.8 & 7.0 & 7.0 & 7.0 \\
\hline Turbidity (NTU) & 309 & 2.09 & 1.67 & 1.82 \\
\hline $\mathrm{SS}\left(\mathrm{mg} \mathrm{L}^{-1}\right)$ & 234 & ND & ND & ND \\
\hline $\mathrm{TS}\left(\mathrm{mg} \mathrm{L}^{-1}\right)$ & 635 & ND & ND & ND \\
\hline $\mathrm{DOC}\left(\mathrm{mg} \mathrm{L}^{-1}\right)$ & 4.1 & 1.776 & 1.304 & 1.318 \\
\hline $\mathrm{UV}_{254}\left(\mathrm{~cm}^{-1}\right)$ & 0.059 & 0.018 & 0.016 & 0.017 \\
\hline $\operatorname{SUVA}^{\mathrm{b}}\left(\mathrm{L} \mathrm{mg}^{-1} \mathrm{~m}^{-1}\right)$ & 1.44 & 1.01 & 1.22 & 1.29 \\
\hline
\end{tabular}

a Permeates at the end of the last coagulation/filtration cycle were collected and analyzed.

b $\mathrm{SUVA}=\mathrm{UV}_{254} / \mathrm{DOC}$.

$\mathrm{PACl}$ coagulant is similar to that used in Hsinchu Water Treatment Plant. Working solutions containing $1000 \mathrm{mg} \mathrm{L}^{-1}$ as Al were freshly prepared before each experiment. The Al concentration was analyzed by inductively coupled plasma-atomic emission spectrometry (ICPAES, JY24, Jobin-Yvon Inc., France). The initial composition of $\mathrm{PACl}$ was determined by Ferron method as reported in our previous study [27]. It is comprised of $42.3 \%$ monomeric $\mathrm{Al}$ $\left(\mathrm{Al}_{\mathrm{a}}\right), 8 \%$ polymeric $\mathrm{Al}\left(\mathrm{Al}_{\mathrm{b}}\right)$, and $49.7 \%$ colloidal $\mathrm{Al}\left(\mathrm{Al}_{\mathrm{c}}\right)$.

\subsubsection{Membrane}

The microfiltration (MF) was performed with a flat sheet of PTFE membrane of which the nominal pore size is $0.5 \mu \mathrm{m}$ with polypropylene as the supporting material (Gore, USA). The diameter of the MF membrane was $5 \mathrm{~cm}$ and the effective filtration area was $0.002 \mathrm{~m}^{2}$.

\subsection{Methods}

\subsubsection{Analysis of water quality}

The $\mathrm{pH}$, suspended solid (SS) and total solid (TS) of SFBW samples were determined by standard methods. Dissolved organic carbon (DOC) was analyzed with a total organic carbon (TOC) analyzer (TOC-5000A, Shimadzu, Japan). Measurement of absorbance at the wavelength of $254 \mathrm{~nm}\left(U_{254}\right)$ was carried out with a spectrophotometer (UV-Vis spectrometer-U3010, Hitachi, Japan). Turbidity was measured with a turbidimeter (Turb555, WTW Co., Germany). Zeta potentials and particles size were determined with a zeta meter (Zetasizer nano ZS, Malvern, UK) and a particle size analyzer (Mastersizer 2000, Malvern, UK), respectively.

\subsubsection{Coagulation experiments}

Standard jar tests were carried out for the coagulation experiments. A square acrylic vessel (dimensions: $11.5 \mathrm{~cm} \times 11.5 \mathrm{~cm} \times 21 \mathrm{~cm})$, was used as a mixing device, and is commonly known as a gator jar. A flat rectangular blade (dimensions: $76 \mathrm{~mm} \times 25 \mathrm{~mm}$ ) driven by a single thin spindle via a motor was located at the center of the vessel. The speed of the motor could be adjusted to $300 \mathrm{rpm}$. Rapid mixing was initially carried out at $200 \mathrm{rpm}\left(G=350 \mathrm{~s}^{-1}\right)$ for $1 \mathrm{~min}$, followed by a slow mixing at $30 \mathrm{rpm}\left(G=25 \mathrm{~s}^{-1}\right)$ for $20 \mathrm{~min}$. After a 20 -min settling period, the supernatant was drawn off to measure turbidity. The coagulant (Al) dosage is expressed in $\mathrm{mg} \mathrm{L}^{-1}$ as $\mathrm{Al}$ in this study. A particle size analyzer (Mastersizer 2000, Malvern, UK), coupled with a small angle laser light scattering (SALLS) was used to observe the aggregation dynamics of particles and size distribution of flocs during coagulation. Fractal dimensions of the coagulated flocs were calculated from the data of SALLS, as reported in our previous study [35]. Floc strength was determined following the procedure reported by Jarvis et al. [36]. The flocs formed after slow mixing were further mixed for $15 \mathrm{~min}$ at four different mixing intensities, 


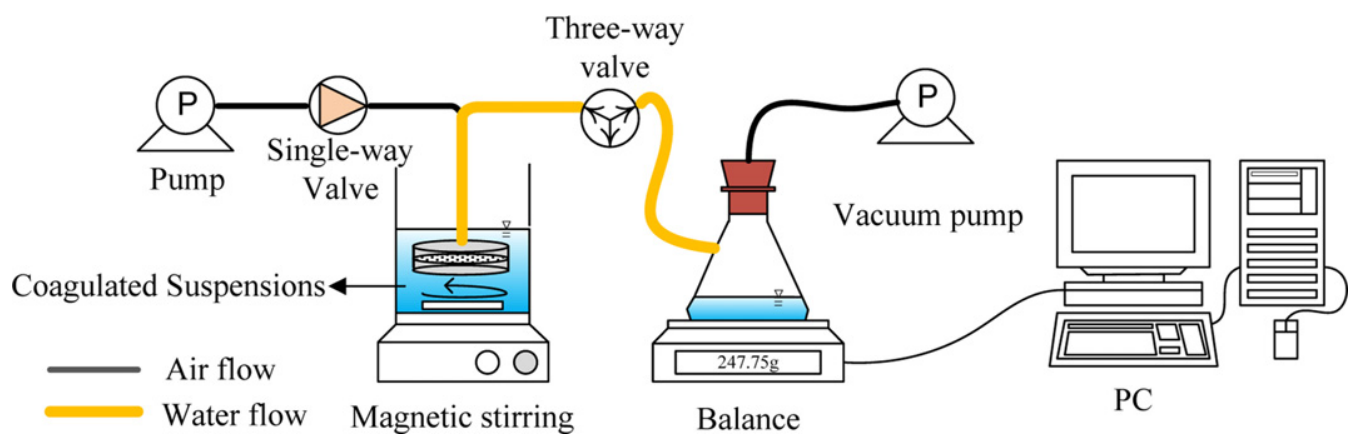

Fig. 1. Schematic diagram of dead-end membrane filtration.

$25 \mathrm{~s}^{-1}, 70 \mathrm{~s}^{-1}, 130 \mathrm{~s}^{-1}$ and $350 \mathrm{~s}^{-1}$, to break up the flocs. The size of the broken flocs after each mixing was measured. The slope of the log-log plot of floc size and the applied shear stress represents floc strength constant.

\subsubsection{Membrane filtration}

The schematic diagram of the dead-end micro-filtration (MF) system used in this study is shown in Fig. 1. After pre-coagulation the suspension was transferred to a 1.5 L flask and was slowly agitated at $30 \mathrm{rpm}$ to retain suspension for the subsequent membrane filtration. A flat sheet MF membrane was fixed in the membrane holder and was then submerged in the suspension, and filtration was carried out at a constant filtration pressure of 0.4 bar, created by a vacuum pump (GAST, USA). The permeate flux was determined by weighing the permeate on an electronic balance, and was recorded simultaneously on a computer equipped with an auto-reading program.

Before each filtration experiment, the new membrane was immersed in ultrapure water for $2 \mathrm{~h}$, followed by the filtration of $1 \mathrm{~L}$ of ultrapure water to remove any impurities. The clean-water flux $\left(J_{0}\right)$ was then measured by filtering the DI water through the membrane. Each experiment comprised nine filtration cycles, and each cycle consisted of a filtration and an air backwash. Filtration was terminated when $0.45 \mathrm{~L}$ filtrate was collected, followed by a pulse of air injected at a pressure of 0.5 bar to remove the cake from the membrane.

To determine cake resistance, an unstirred cell unit process was set up as illustrated in Fig. 2. Each coagulated suspension was transferred into the unstirred cell, and membrane flux was recorded with trans-membrane pressure (TMP) ranging from 0.13 to 0.53 bar. Pressure was provided by nitrogen. The result was used to determine various resistances of membrane filtration, adopting the resistance-in-series model. The relationship between permeate flux and resistances can be expressed as Eq. (1):

$J=\frac{\Delta P}{\mu R_{t}}=\frac{\Delta P}{\mu\left(R_{m}+R_{f}+R_{c}\right)}$

where $J$ is the permeate flux, $\Delta P$ is the TMP, $\mu$ is viscosity of permeate, $R_{t}, R_{m}, R_{c}$ and $R_{f}$ are total resistance, membrane resistance, cake resistance and fouling resistance, respectively.

$R_{m}, R_{f}$ and $R_{c}$ can be calculated from Eq. (2)-(4), in which $J_{0}$ is clean water flux, $J_{1}$ is flux of coagulated samples and $J_{2}$ is clean water flux after backwash of the filtered membrane.

$R_{m}=\frac{\Delta P}{\mu J_{0}}$

$R_{f}=\frac{\Delta P}{\mu J_{2}}-R_{m}$

$R_{C}=\frac{\Delta P}{\mu J_{1}}-R_{m}-R_{f}$

Specific cake resistance, $\alpha$, is related to cake resistance, $R_{c}$, and the mass of cake deposited on the membrane surface, $M$, as illustrated in Eq. (5):

$R_{c}=\frac{\alpha \times M}{A_{m}}=\frac{\alpha V C_{b}}{A_{m}}$

where $A_{m}$ is the membrane area, $V$ is the cumulative permeate volume, and $C_{b}$ is the bulk concentration of particles.

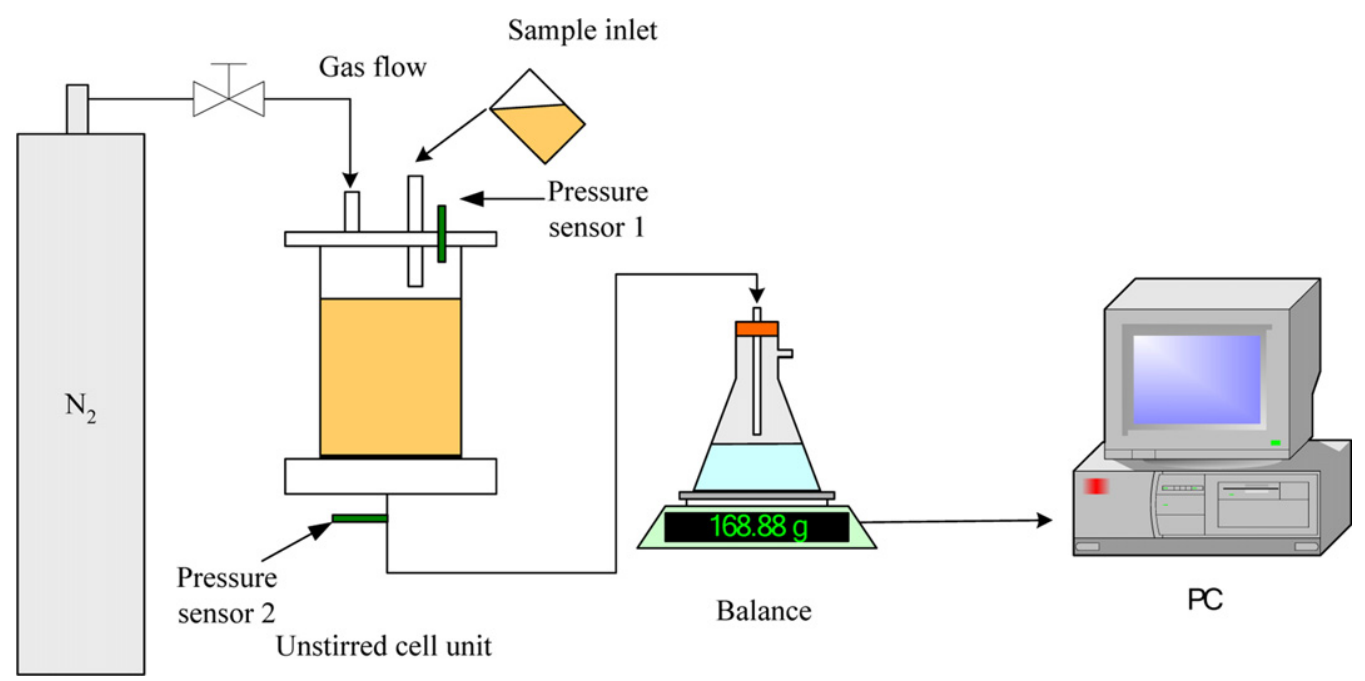

Fig. 2. Schematic diagram of a batch unstirred cell for the determination of cake compressibility index. 

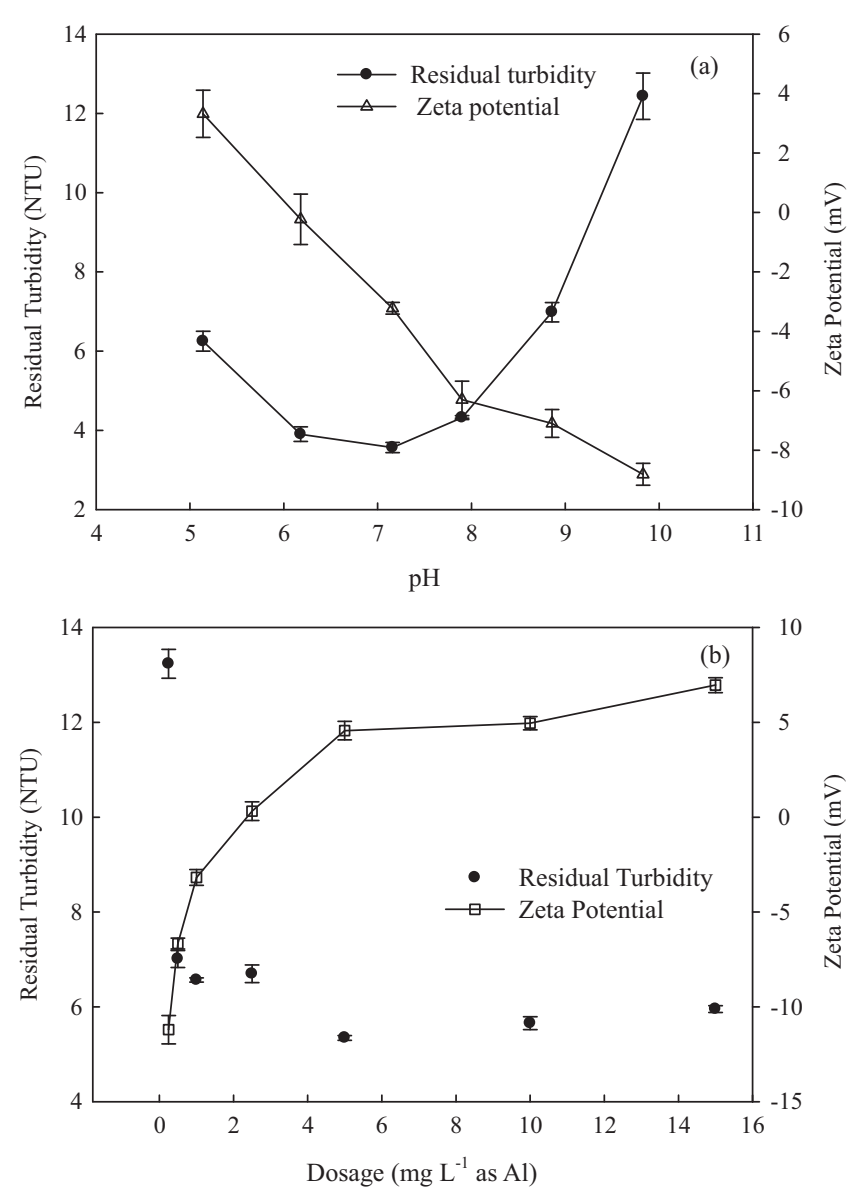

Fig. 3. Destabilization of SFBW particles by PACl coagulation. (a) Variation of residual turbidity and zeta potential with $\mathrm{pH}$ at dosage of $1 \mathrm{mg} \mathrm{L}^{-1}$ as Al. (b) Variation of residual turbidity and zeta potential with dosage at neutral $\mathrm{pH}$.

$\alpha$ was used to determine the compressibility of the cake by a power law [20], where

$\alpha=\alpha_{0} \times \Delta P^{n}$

$\alpha_{0}$ is an empirical constant which represents specific cake resistance in the absence of TMP and $n$ is the compressibility index. Thus, the slope of the linear fit to the logarithmic plots of $\alpha$ at various $\Delta P$ gives the value of $n$.

\section{Results and discussion}

\subsection{Effect of coagulation mechanism on the destabilization of SFBW suspensions}

In a hybrid coagulation/membrane process, coagulation mechanisms dominate the performance of subsequent membrane filtration. Coagulation mechanisms are strongly affected by operation parameters such as $\mathrm{pH}$ and dosage [20]. In this study the $\mathrm{pH}$ effect on coagulation efficiency was first investigated at a constant $\mathrm{PACl}$ dosage of $1 \mathrm{mg} \mathrm{L}^{-1}$ as Al. The optimum $\mathrm{pH}$ was found around neutral $\mathrm{pH}$, where the lowest residual turbidity was obtained, as shown in Fig. 3a. This could be explained by the variation of hydrolyzed $\mathrm{Al}$ species with $\mathrm{pH}$. The PACl applied in this study contained a large fraction of monomeric Al species, which formed hydrolyzed $\mathrm{Al}(\mathrm{OH})_{3}$ at neutral $\mathrm{pH}$ [27]. Our work also indicated that the amounts of hydrolyzed $\mathrm{Al}(\mathrm{OH})_{3}$ was a critical factor in determining the coagulation mechanism [35]. To verify this hypothesis, coagulation performance of SFBW at various dosages was determined. The variation of residual turbidity and zeta potential with the dosage at neutral $\mathrm{pH}$ is illustrated in Fig. 3b. At dosages higher than $5 \mathrm{mg} \mathrm{L}^{-1}$ as $\mathrm{Al}$, consistent turbidity removal was observed, even though charge reversal of particles occurred. It suggested that the turbidity removal at overdosing was most likely due to sweep flocculation (SW) in which particles were entrapped in the growing $\mathrm{Al}(\mathrm{OH})_{3}$ precipitates [28]. On the other hand, efficient turbidity removal at a low dosage of $2.5 \mathrm{mg} \mathrm{L}^{-1}$ where zeta potential closed to zero, suggesting particle destabilization was caused by charge neutralization $(\mathrm{CN})$.

When the dosage was as low as $0.5 \mathrm{mg} \mathrm{L}^{-1}$ as $\mathrm{Al}$, satisfactory turbidity removal occurred. The corresponding more positive zeta potential suggested that particle coagulation was caused by positively charged $\mathrm{Al}(\mathrm{OH})_{3}$ through precipitation charge neutralization (PCN), when such a low dosage of positively charged $\mathrm{Al}(\mathrm{OH})_{3}$ was present $[35,37]$. Wang et al. [31] have demonstrated that particles were effectively destabilized by $\mathrm{Al}(\mathrm{OH})_{3}$ precipitates even when the negatively charged particles were weakly neutralized. Furthermore, the high concentration of particles in SFBW improved the PCN effect on coagulation due to the high collision frequency between particles, which results in satisfactory turbidity removal. The results imply that the dosage of $\mathrm{PACl}$ can dictate the aggregation of SFBW particles and the predominant coagulation mechanisms at neutral $\mathrm{pH}$. The following experiment was designed to correlate the relationship between coagulation mechanism and the performance of membrane filtration.

\subsection{Effect of coagulation mechanism on membrane filtration}

Enlarging submicron particles of SFBW by pre-coagulation is crucial to enhance flux in membrane filtration [34]. To investigate the effect of pre-coagulation mechanisms on the membrane filtration of SFBW, the coagulated suspensions formed by PCN, CN and SW were subjected to a dead-end MF membrane filtration process, as described below. As can be seen in Fig. 3, the dosage for the coagulation mechanism of $\mathrm{PCN}, \mathrm{CN}$ and $\mathrm{SW}$ was $0.5,2.5$ and $5 \mathrm{mg} \mathrm{L}^{-1}$ as Al, respectively. Nine filtration cycles were conducted to ascertain the long-term effect of pre-coagulation mechanism on membrane filtration. Permeate was collected and analyzed at the end of the last coagulation/membrane filtration cycle. Permeate quality is the key to the effective SFBW recycling in a coagulation/membrane filtration process. The quality of the permeates was compared with that of the raw water, as summarized in Table 1. No significant difference was observed among the permeates from three pre-coagulation mechanisms. The turbidity of the permeates was less than $2 \mathrm{NTU}$, indicating the effective turbidity removal of SFBW by coagulation/dead-end microfiltration process. By contrast, $30-40 \%$ of DOC still remained in the permeate. Other studies on the removal of dissolved organic matter (DOM) by coagulation have given different results. Zhang et al. [38] recorded that the DOM aggregated into clusters after pre-coagulation, which effectively facilitated their rejection by MF membrane. Pikkarainen et al. [39] found that pre-coagulation enhanced the DOC removal in upland surface water by more than $80 \%$ in a coagulation-assisted MF process. In our coagulation/dead-end MF process, on the other hand, the highest removal of $\mathrm{DOC}$ and $\mathrm{UV}_{254}$ was $68 \%$ and $72 \%$, respectively, which could be explained by the much lower SUVA value of the DOM [40]. As shown in Table 1, the SUVA value of SFBW was about 1.4 (less than 2), suggesting that the DOM in SFBW are low molecular weight and low hydrophobicity. As a result, the DOM was hard to aggregate by coagulation, leading to poor DOM rejection in the subsequent microfiltration.

In practice, permeate flux is the main concern in SFBW recycling by membrane operation. The relative mean flux $\left(J / J_{0}\right)$ of the MF membrane for nine successive filtration cycles is plotted in Fig. 4, showing marked difference before and after coagulation. Permeate flux was significantly improved through pre-coagulation, and 


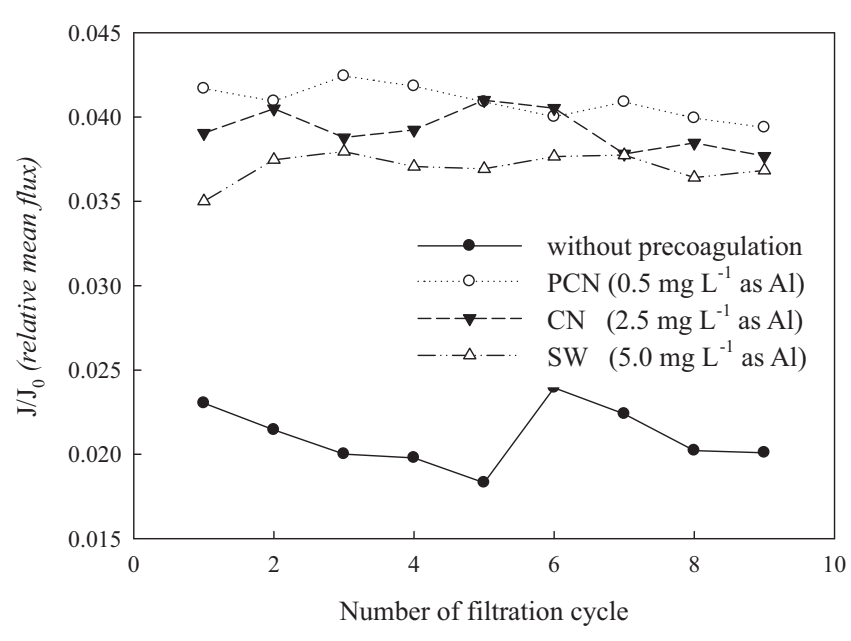

Fig. 4. Variation of relative mean flux of coagulated suspensions formed from various coagulation conditions with filtration cycles of the dead-end microfiltration.

the flux improvement by PCN is consistently more effective, followed by CN. This could be explained by the characteristics of the cake layer. Lee et al. [20] have demonstrated that the porosity of the cake layer formed on the membrane from $\mathrm{CN}$ suspension is larger than those from SW suspension, which might explain the delayed TMP buildup at a steady-state flux for CN coagulation. Other studies have proposed that pre-coagulation mechanisms can mitigate membrane fouling due to their effect on cake layer characteristics [24,41]. Judd and Hills [42] proposed that cake layer formation dominates the magnitude of irreversible fouling, while other researchers have found that cake porosities are mainly affected by the properties of pre-coagulated flocs such as size and fractal dimension [23]. It is thus hypothesized that the enhanced flux by pre-coagulation is strongly related to the characteristics of the pre-coagulated SFBW flocs, which determines the subsequent cake layer on membrane surfaces. In other words, flocs formed from pre-coagulation could influence indirectly the performance of membrane filtration, which was verified in the next experiment.

\subsection{Effect of floc properties on membrane permeability}

To study the effect of coagulated SFBW floc properties on membrane filtration, the size of the flocs by coagulation through PCN, CN and SW was monitored by SALLS for a period of $20 \mathrm{~min}$. The results are shown in Fig. 5. The growth profiles of flocs during coagulation differed markedly with various coagulation mechanisms. The floc formed by SW coagulation was the largest and grew the fastest. The profile was also accompanied by the greatest breakage rate. Jarvis et al. [36] have reported that larger flocs contain larger porosity and are easily broken by surface erosion of eddies splitting. As a result, the obvious breakage of the SW flocs occurred during flocculation. To examine the effect of floc structure on the subsequent membrane filtration, fractal dimensions $\left(d_{f}\right)$ of flocs were determined from the data given by SALLS. The $d_{f}$ of the PCN, CN and SW flocs are 2.14, 2.06 and 1.90, respectively, as shown in Fig. 5. The results indicate that the SW flocs are the largest and loosest. In general, large flocs form cakes with high porosity and low cake resistance, which is favorable for membrane filtration. Other studies have reported that higher membrane flux accompanying low cake resistance is associated with large floc or low $d_{f}[22,24]$. However, in our study, the lowest membrane flux occurred in the largest SW flocs with the lowest $d_{f}$, as shown in Fig. 4 . The results suggested that membrane filtration can be affected by parameters other than size and $d_{f}$ of flocs.

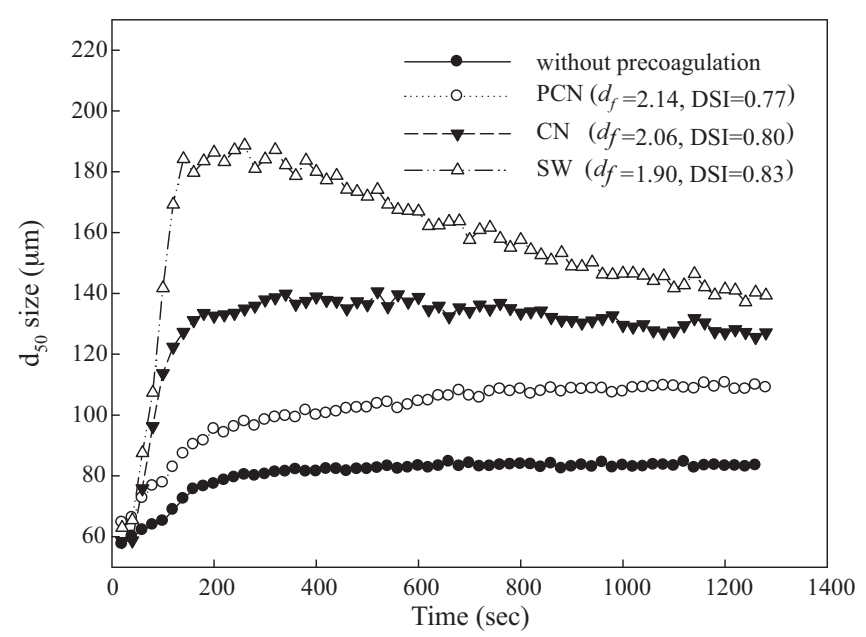

Fig. 5. Variation of floc size $\left(d_{50}\right)$ with flocculation time for coagulated SFBW at $\mathrm{pH}$ 7. The distribution spread index (DSI) of floc size is expressed by the ratio $\left(d_{90}-d_{10}\right) / 2\left(d_{50}\right) \cdot d_{90}$ : diameter corresponding to $90 \%$ of cumulative undersize; $d_{10}$ : diameter corresponding to $10 \%$ of cumulative undersize; $d_{50}$ : median diameter.

Barbot et al. [43] suggested that the optimal pre-coagulation condition for coagulation/membrane filtration process is the formation of large flocs with strong structure. Strong flocs can resist the shear stress of fluid during filtration, which facilitates the flow between aggregates within cake. To verify this, the flocs formed through the process of PCN, CN and SW coagulation were agitated for $15 \mathrm{~min}$ with different breaking intensities. The floc strength constants were calculated from the slope of the log-log plot of floc size and the applied shear stress. Higher floc strength constants means that flocs are easier to break by shear forces [36]. As shown in Fig. 6, floc strength constants of PCN, CN and SW flocs are 0.114, 0.158 and 0.173 , respectively, indicating that $\mathrm{PCN}$ flocs are the strongest. Lee et al. [44] have reported that strong flocs with compact structure as well as small size can form cake layer of high permeability in membrane filtration. In our study, because PCN flocs are the strongest, most compact and smallest, the most enhanced flux was observed in PCN coagulation, as evidenced in Fig. 4. The results implied that the strength of SFBW flocs can influence the cake permeability and the performance of membrane filtration.

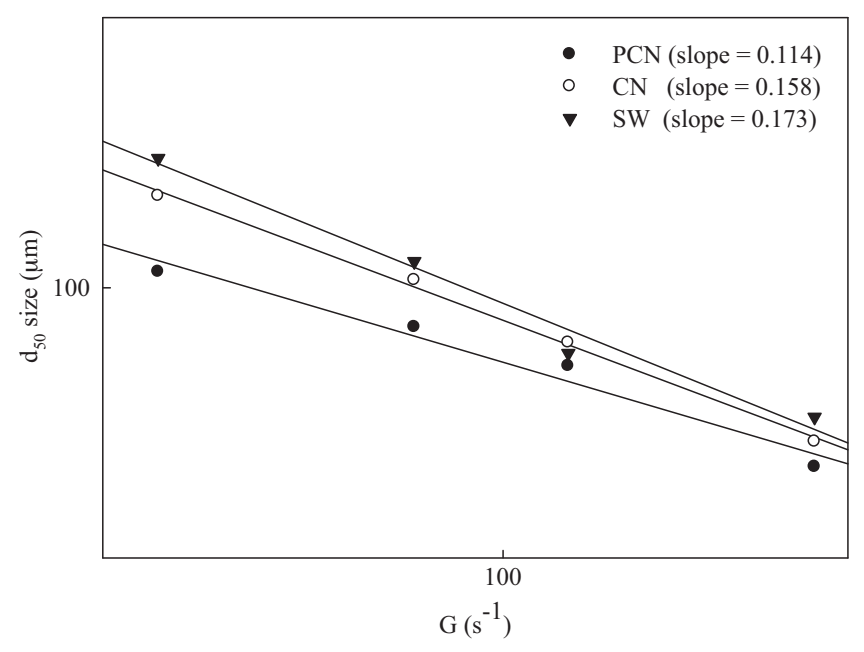

Fig. 6. Variation of the size $\left(d_{50}\right)$ of floc formed from different coagulation mechanisms with breaking intensity. The slope represents floc strength constant. 
Table 2

Membrane filtration resistance of SFBW flocs formed from various coagulation conditions with filtration pressure of 0.4 bar over 9 cycles.

\begin{tabular}{llccl}
\hline $\begin{array}{l}\text { Coagulation } \\
\text { conditions }\end{array}$ & \multicolumn{4}{l}{ Membrane filtration resistance $^{\mathrm{a}}$} \\
\cline { 2 - 5 } & $R_{m}(\%)$ & $R_{f}(\%)$ & $R_{c}(\%)$ & $R_{t}\left(\mathrm{~m}^{-1}\right)$ \\
\hline $\mathrm{PCN}$ & 4 & $3 \sim 13$ & $93 \sim 83$ & $5.04 \times 10^{9} \sim 5.43 \times 10^{9}$ \\
$\mathrm{CN}$ & 4 & $3 \sim 13$ & $93 \sim 83$ & $5.15 \times 10^{9} \sim 5.61 \times 10^{9}$ \\
$\mathrm{SW}$ & 4 & $3 \sim 12$ & $93 \sim 84$ & $5.82 \times 10^{9} \sim 6.31 \times 10^{9}$ \\
Without & 2 & $3 \sim 9$ & $95 \sim 89$ & $8.76 \times 10^{9} \sim 1.15 \times 10^{10}$ \\
$\quad$ coagulation & & & & \\
\hline
\end{tabular}

${ }^{a} R_{m}, R_{f}, R_{c}$, and $R_{t}$ of the cake formed from flocs through various coagulation conditions were calculated by the resistance-in-series model.

\subsection{Effect of cake properties on membrane permeability}

Cake resistance is generally the primary resistance in coagulation/membrane filtration. Based on the resistance-in-series model, various resistances (i.e., $R_{m}, R_{f}, R_{c}$ and $R_{t}$ ) were calculated by Eq. (1) in our coagulation/membrane filtration process. The resistances are summarized in Table 2 . It is clear that most membrane resistance comes from cake resistance, $R_{c}$, suggesting that the property of cake layer plays a critical role in cake permeability. On the other hand, because particles $<0.5 \mu \mathrm{m}$ was less than $5 \%$ by volume in each coagulated sample, pore-blocking was considered minor during membrane filtration, echoing the results in Table 2.

Research has also suggested that during filtration, cakes containing higher cake compressibility lead to lower cake porosity and higher specific cake resistance, which reduces the cake permeability [20]. In order to explore the relationship between cake compressibility and membrane flux in coagulation/dead-end microfiltration, specific cake resistances as it varied with TMP was determined, and is shown in Fig. 7. Cake compressibility $(n)$ is the slope of the log-log plot of specific cake resistances and TMP, where the slope of PCN, CN and SW flocs are $0.82,0.92$ and 1.15, respectively. The result proved that SW flocs are more compressible in structure, which produce more compact cake layer in the subsequent filtration process. Although cake layers formed by larger flocs usually have higher porosity, this results in lower specific cake resistance. However, due to the very loose structure of SW flocs, the flocs are easily compressed by the pressure applied during filtration, resulting in higher specific cake resistance. On the other hand, strong $\mathrm{PCN}$ and $\mathrm{CN}$ flocs produce less compressible cake during membrane filtration, resulting in the high membrane permeability.

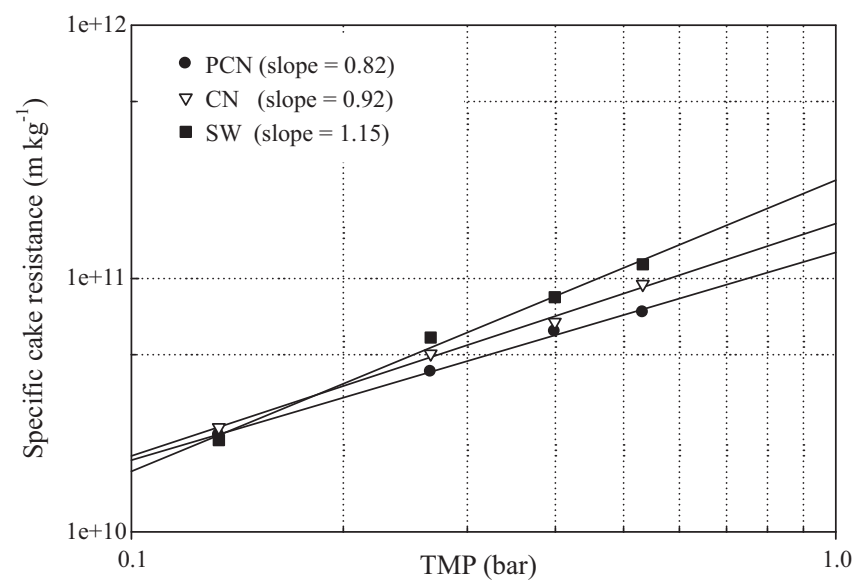

Fig. 7. Variation of specific cake resistance of flocs formed from various coagulation mechanisms with TMP in unstirred cell filtration. The slope represents compressibility index $(n)$.
Bizi [25] noticed that in addition to cake porosity, distribution spreading index (DSI) of floc size distribution also played a critical role in specific cake resistance, where the minimum specific cake resistance occurred at the highest cake porosity and lowest DSI. Higher DSI means the broader size distribution of particles. In our study the minimum specific resistance occurs in PCN coagulation, as seen in Fig. 7, while the PCN flocs bore the minimum DSI, as illustrated in Fig. 5. As a result, the enhanced flux by PCN coagulation exceeded those by $\mathrm{CN}$ and SW coagulation.

The exploration of the relationship between floc properties and the corresponding cake properties indicated that stronger SFBW flocs of smaller size and lower DSI tended to form cakes of low compressibility, resulting in high membrane permeability and high flux in coagulation/membrane filtration process.

\section{Conclusions}

Pre-coagulation can enhance the permeate flux of dead-end MF membrane in coagulation-assisted membrane filtration for SFBW recycling with satisfactory permeate quality, regardless of coagulant dosage. However, pre-coagulation mechanisms govern the membrane flux of the subsequent microfiltration. The most efficient membrane flux improvement is induced by PCN. The structure of SFBW flocs determines the characteristics of cake and cake resistance, which is the key to flux improvement. In addition, the DSI of SFBW floc size is closely related to the performance of membrane filtration. SFBW flocs by PCN are smaller and stronger, with a lower DSI value, resulting in lower specific cake resistance to membrane filtration. To maximize the performance of coagulation/membrane filtration for SFBW recycling, the coagulation must produce strong flocs with low DSI to lower the specific cake resistance of the membrane filtration.

\section{Acknowledgements}

The research was supported by the grant of National Science Council (93-2622-E-009-006-CC3). The authors are also grateful to Taiwan Water Cooperation for assistance in spent filter backwash water sampling.

\section{References}

[1] D.A. Cornwell, M.J. MacPhee, Effects of spent filter backwash recycle on Cryptosporidium removal, J. Am. Water Works Assoc. 93 (2001) 153-162.

[2] J.K. Edzwald, J.E. Tobiason, Fate and removal Cryptosporidium in a dissolved air flotation water plant with and without recycle of waste filter backwash water Water Sci. Technol.: Water Supply 2 (2002) 85-90.

[3] M.E. Walsh, G.A. Gagnon, Z. Alam, R.C. Andrews, Biostability and disinfectant by-product formation in drinking water blended with UF-treated filter backwash water, Water Res. 42 (2008) 2135-2145.

[4] A. Adin, L. Dean, F. Bonner, A. Nasser, Z. Huberman, Characterization and destabilization of spent filter backwash water particles, Water Sci. Technol.: Water Supply 2 (2002) 115-122.

[5] AWWA, Background papers on potential recycle streams in drinking water treatment plant, 1999.

[6] J.C. Bourgeois, M.E. Walsh, G.A. Gagnon, Comparison of process options for treatment of water treatment residual streams, J. Environ. Eng. Sci. 3 (2004) 477-484.

[7] H. Arora, G. Di-Giovanni, M. LeChevallier, Spent filter backwash water contaminants and treatment strategies, J. Am. Water Works Assoc. 93 (2001) 100-112.

[8] D.A. Cornwell, R.G. Lee, Waste stream recycling-its effect on water-quality, J. Am. Water Works Assoc. 86 (1994) 50-63.

[9] USEPA, Filter Backwash Recycling Rule Technical Guidance Manual, 2002.

[10] M.T. Hung, J.C. Liu, Reclamation of backwash water by cross flow microfiltration- a case study, J. Water Supply Res. Technol. AQUA 56 (2007) 479-493.

[11] M.E. Walsh, G.A. Gagnon, Blending membrane treated WTP waste residuals with finished water: impacts to water quality and biofilm formation, J. Water Supply Res. Technol. AQUA 55 (2006) 321-334.

[12] Y.A. LeGouellec, D.A. Cornwell, M.J. MacPhee, Treating microfiltration backwash, J. Am. Water Works Assoc. 96 (2004) 72-83.

[13] F.G. Reissmann, W. Uhl, Ultrafiltration for the reuse of spent filter backwash water from drinking water treatment, Desalination 198 (2006) 225-235. 
[14] R.J.N. Willemse, Y. Brekvoort, Full-scale recycling of backwash water from sand filters using dead-end membrane filtration, Water Res. 33 (1999) 3379-3385.

[15] Y. Chen, B.Z. Dong, N.Y. Gao, J.C. Fan, Effect of coagulation pretreatment on fouling of an ultrafiltration membrane, Desalination 204 (2007) 181-188.

[16] C. Guigui, J.C. Rouch, L. Durand-Bourlier, V. Bonnelye, P. Aptel, Impact of coagulation conditions on the in-line coagulation/UF process for drinking water production, Desalination 147 (2002) 95-100.

[17] K.J. Howe, A. Marwah, K.P. Chiu, S.S. Adham, Effect of coagulation on the Size of MF and UF membrane foulants, Environ. Sci. Technol. 40 (2006) 7908-7913.

[18] P. Park, C. Lee, S.J. Choi, K.H. Choo, S.H. Kim, C.H. Yoon, Effect of the removal of DOMs on the performance of a coagulation-UF membrane system for drinking water production, Desalination 145 (2002) 237-245.

[19] K. Kimura, T. Maeda, H. Yamamura, Y. Watanabe, Irreversible membrane fouling in microfiltration membranes filtering coagulated surface water, J. Membr. Sci. 320 (2008) 356-362.

[20] J.D. Lee, S.H. Lee, M.H. Jo, P.K. Park, C.H. Lee, J.W. Kwak, Effect of coagulation conditions on membrane filtration characteristics in coagulation-microfiltration process for water treatment, Environ. Sci. Technol. 34 (2000) 3780-3788.

[21] J. Wang, J. Guan, S.R. Santiwong, T.D. Waite, Characterization of floc size and structure under different monomer and polymer coagulants on microfiltration membrane fouling, J. Membr. Sci. 321 (2008) 132-138.

[22] S.A. Lee, A.G. Fane, R. Amal, T.D. Waite, The effect of floc size and structure on specific cake resistance and compressibility in dead-end microfiltration, Sep. Sci. Technol. 38 (2003) 869-887.

[23] P.K. Park, C.H. Lee, S. Lee, Permeability of collapsed cakes formed by deposition of fractal aggregates upon membrane filtration, Environ. Sci. Technol. 40 (2006) 2699-2705.

[24] S. Veerapaneni, M.R. Wiesner, Hydrodynamics of fractal aggregates with radially varying permeability, J. Colloid Interface Sci. 177 (1996) 45-57.

[25] M. Bizi, Filtration characteristics of a mineral mud with regard to turbulent shearing, J. Membr. Sci. 320 (2008) 533-540.

[26] A.W. Zularisam, A.F. Ismail, M.R. Salim, M. Sakinah, T. Matsuura, Application of coagulation-ultrafiltration hybrid process for drinking water treatment: optimization of operating conditions using experimental design, Sep. Purif. Technol. 65 (2009) 193-210.

[27] J.L. Lin, C.P. Huang, J.R. Pan, D.S. Wang, Effect of Al (III) speciation on coagulation of highly turbid water, Chemosphere 72 (2008) 189-196.

[28] J. Duan, J. Gregory, Coagulation by hydrolysing metal salts, Adv. Colloid Interface Sci. 100 (2003) 475-502.
[29] J.L. Lin, C.J.M. Chin, C.P. Huang, J.R. Pan, D.S. Wang, Coagulation behavior of $\mathrm{Al}_{13}$ aggregates, Water Res. 42 (2008) 4281-4290.

[30] J.L. Lin, C.P. Huang, C.J.M. Chin, J.R. Pan, The origin of $\mathrm{Al}(\mathrm{OH})_{3}$-rich and $\mathrm{Al}_{13}$-aggregate flocs composition in $\mathrm{PACl}$ coagulation, Water Res. 43 (2009) 4285-4295.

[31] D.S. Wang, H.X. Tang, J. Gregory, Relative importance of charge neutralization and precipitation on coagulation of kaolin with PACl: effect of sulfate ion, Environ. Sci. Technol. 36 (2002) 1815-1820.

[32] A. Nasser, Z. Huberman, L. Dean, F. Bonner, A. Adin, Coagulation as a pretreatment of SFBW for membrane filtration, Water Supply 2 (2002) 301-306.

[33] H. Song, X. Fan, Y. Zhang, T. Wang, Y. Feng, Application of microfiltration for reuse of backwash water in a conventional water treatment plant-a case study, Water Supply 1 (2001) 199-206.

[34] C.P. Huang, J.L. Lin, C.L. Wu, C.P. Chu, Recycling of spent filter backwash water using coagulation-assisted membrane filtration: effects of submicron particles on membrane flux, Water Sci. Technol. 61 (2010) 1923-1929.

[35] J.L. Lin, C.P. Huang, C.J.M. Chin, J.R. Pan, Coagulation dynamics of fractal flocs induced by enmeshment and electrostatic patch mechanisms, Water Res. 42 (2008) 4457-4466.

[36] P. Jarvis, B. Jefferson, J. Gregory, S.A. Parsons, A review of floc strength and breakage, Water Res. 39 (2005) 3121-3137.

[37] S.K. Dentel, Application of the precipitation charge neutralization model of coagulation, Environ. Sci. Technol. 22 (1988) 825-832.

[38] L.L. Zhang, D. Yang, Z.J. Zhong, P. Gu, Application of hybrid coagulationmicrofiltration process for treatment of membrane backwash water from waterworks, Sep. Purif. Technol. 62 (2008) 415-422.

[39] A.T. Pikkarainen, S.J. Judd, J. Jokela, L. Gillberg, Pre-coagualtions for microfiltration of an upland surface water, Water Res. 38 (2004) 455-465.

[40] K. Kimura, Y. Hane, Y. Watanbe, Effect of pre-coagulation on mitigating irreversible fouling during ultrafiltration of a surface water, Water Sci. Technol. 51 (2005) 93-100.

[41] K.Y.J. Choi, B.A. Dempsey, In-line coagulation with low-pressure membrane filtration, Water Res. 38 (2004) 4271-4281.

[42] S.J. Judd, P. Hills, Optimisation of combined coagulation and microfiltration for water treatment, Water Res. 35 (2001) 2895-2904.

[43] E. Barbot, S. Moustier, J.Y. Bottero, P. Moulin, Coagulation ultrafiltration: understanding of the key parameters of the hybrid process, J. Membr. Sci. 325 (2008) 520-527.

[44] S.Y.A. Lee, A.G. Fane, T.D. Waite, Impact of natural organic matter on floc size and structure effects in membrane filtration, Environ. Sci. Technol. 39 (2005) 6477-6486. 